\title{
Using Cavitation Peening to Improve the Fatigue Life of Titanium Alloy Ti-6Al-4V Manufactured by Electron Beam Melting
}

\author{
Mitsuru Sato', Osamu Takakuwa1, Masaaki Nakai'2, Mitsuo Niinomi², Fumio Takeo ${ }^{3}$, \\ Hitoshi Soyama ${ }^{1}$ \\ ${ }^{1}$ Department of Nanomechanics, Graduate School of Engineering, Tohoku University, Sendai, Japan \\ ${ }^{2}$ Institute for Materials Research, Tohoku University, Sendai, Japan \\ ${ }^{3}$ Department of Mechanical Engineering, Hachinohe National College of Technology, Hachinohe, Japan \\ Email: o_takakuwa@mm.mech.tohoku.ac.jp
}

Received 4 February 2016; accepted 15 April 2016; published 20 April 2016

Copyright (C) 2016 by authors and Scientific Research Publishing Inc.

This work is licensed under the Creative Commons Attribution International License (CC BY).

http://creativecommons.org/licenses/by/4.0/

(c) (i) Open Access

\section{Abstract}

Although Electron Beam Melting (EBM) is an innovative technology, the fatigue properties of materials manufactured by EBM may be lower than those of casted and wrought materials due to defects and surface roughness. In order to enhance the fatigue life of components or structures manufactured by EBM, a mechanical surface treatment technology, e.g., peening, would be effective because peening introduces high compressive residual stress at the surface which can extend the fatigue life considerably. In the present study, specimens were manufactured by EBM using titanium alloy Ti-6Al-4V powder. Two types of specimens were prepared: as-built and as-machined specimens. Specimens of each type were treated by cavitation peening or shot peening. The fatigue lives of the specimens were evaluated by a plate bending fatigue tester. The residual stress and surface roughness were also evaluated. The results obtained showed that the fatigue strength of as-built specimens can be improved by $21 \%$ by cavitation peening or shot peening, and the fatigue life under particular applied stresses can also be extended by $178 \%$ by cavitation peening.

\section{Keywords}

Component, Electron Beam Melting, Ti-6Al-4V, Cavitaion Peening, Residual Stress, Fatigue

\section{Introduction}

Recently, Electron Beam Melting (EBM) has been developed as an innovative technology for the rapid manu-

How to cite this paper: Sato, M., Takakuwa, O., Nakai, M., Niinomi, M., Takeo, F. and Soyama, H. (2016) Using Cavitation Peening to Improve the Fatigue Life of Titanium Alloy Ti-6Al-4V Manufactured by Electron Beam Melting. Materials Sciences and Applications, 7, 181-191. http://dx.doi.org/10.4236/msa.2016.74018 
facturing of three dimensional components with complex geometries. Complete designs can be directly and freely done [1]. Due to these advantages, the demand for EBM in the aviation and medical industrial fields has risen. One of the advantages of EBM, which is due to its higher output and higher scanning velocity, is the rapidity with which three dimensional components can be manufactured compared to other additive manufacturing technologies, e.g., laser beam melting [2]. In contrast, it has been found that the fatigue performance of materials produced by additive manufacturing is lower than that of casted or wrought materials because of their porosity and surface roughness [3] [4]. For this reason, the fatigue properties of EBM materials are also no better than those manufactured by other additive manufacturing technologies [5]. Therefore, the fatigue properties of components manufactured by EBM are needed to be improved after manufacture.

To enhance the fatigue properties, some mechanical surface treatment technologies have been developed, e.g., shot peening and cavitation peening. Peening introduces compressive residual stress due to impact at the surface, inducing local plastic deformation. The residual stress in the surface layer has a significant effect on the fatigue properties, i.e., crack initiation and propagation, in metallic materials [6]. A tensile residual stress promotes fatigue fracture while a compressive residual stress does the opposite. In past studies, it has been demonstrated that the compressive residual stress introduced by peening prevents fatigue crack propagation in metallic materials [7]. The residual stress also affects chemical reactions on the surface. The resistance to corrosion can also be improved by controlling the residual stress [8].

Shot peening is a conventional mechanical surface treatment that utilizes the impact produced when solid bodies collide with the surface [9]. An innovative mechanical surface treatment, cavitation peening, utilizes the impact produced by shock waves in water caused by cavitation bubbles collapsing [10]. It can be utilized in the same way as shot peening. The cavitation bubbles are produced by injecting a high-speed water jet into water. Cavitation clouds spread out across the surface under treatment. When the bubbles collapse, they produce impacts which cause local plastic deformation on the surface. The intensity of the cavitation impacts can be controlled by several hydraulic parameters and the nozzle outlet geometry [11].

Cavitation peening has some advantages compared to conventional shot peening. Firstly, the surface roughness produced by cavitation peening is less than that produced by shot peening because there are no solid collisions [12]. Secondly, cavitation peening does not require the chemical cleaning which is needed to remove iron adhering to the surface when shot peening is applied, since cavitation peening uses only water. Thirdly, cavitation peening can be used to treat surfaces in narrow spaces where shot cannot reach, e.g., fastener holes in aircraft components [13], the bottoms of gears [14] or elements of the steel belts used for Continuously Variable Transmission (CVT) [15].

As mentioned above, the components manufactured by EBM need to be improved in terms of their fatigue properties, and cavitation peening has the potential to do this. In the present study, titanium alloy Ti-6Al-4V was employed, which was often used for high value-added products, e.g., medical products and/or aerospace products. In order to demonstrate this, plate bending fatigue tests were conducted on Ti-6Al-4V plate specimens manufactured by EBM after cavitation peening or shot peening. Additionally, as-built specimens and specimens whose surfaces were ground to remove surface roughness, i.e., as-machined specimens, were tested. The compressive residual stress at the surface introduced by peening was evaluated by X-ray diffraction stress measurements.

\section{Experimental Facilities and Procedures}

Figure 1 shows a schematic diagram of the cavitation peening system used in the experiment [16]. Water stored in tank B is pressurized by a plunger pump with a maximum pressure of $35 \mathrm{MPa}$ and maximum discharge of $3.0 \times$ $10^{-2} \mathrm{~m}^{3} / \mathrm{min}$. The pressurized water is injected into a water filled chamber, i.e., tank A, through a nozzle immersed in water in the test section. A floating plate is located near the nozzle to avoid suction vortices. The nozzle is equipped with a cavitator and a guide pipe in order to enhance the aggressive intensity of the cavitating jet as shown in Figure 2. The geometry of the nozzle has been previously optimized [16]. The test section is open to the ambient air. As residual bubbles which remain after the cavitation bubbles have collapsed might reduce the shock wave, a partition plate is placed in tank B to remove residual bubbles remaining in the test water [17]. The geometrical parameters of the nozzle are given in Table 1 . The injection pressure $p_{1}$ was kept constant at 30 $\mathrm{MPa}$ and the ambient pressure of the jet, $p_{2}$, is equal to atmospheric pressure $(0.1 \mathrm{MPa})$. The standoff distance from the upstream end of the nozzle plate to the surface of the specimen was $262 \mathrm{~mm}$ by reference to the 


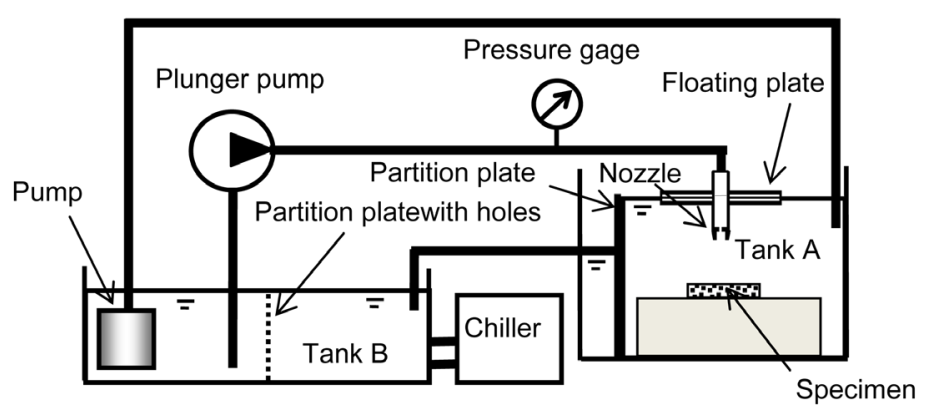

Figure 1. Schematic diagram of the cavitation peening system.

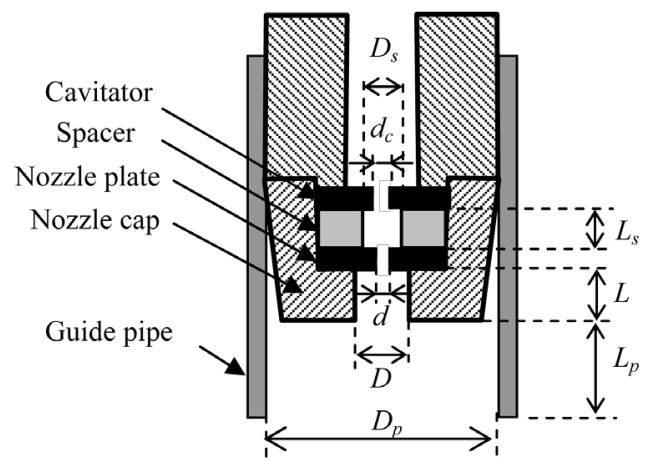

Figure 2. Nozzle for cavitation peenig.

Table 1. Geometry of the nozzle for cavitation peening.

\begin{tabular}{ccc}
\hline Nozzle diameter & $d$ & $2 \mathrm{~mm}$ \\
Cavitator diameter & $d_{c}$ & $3 \mathrm{~mm}$ \\
Spacer diameter & $D_{s}$ & $6 \mathrm{~mm}$ \\
Spacer length & $L_{s}$ & $6 \mathrm{~mm}$ \\
Outlet bore diameter & $D$ & $16 \mathrm{~mm}$ \\
Oulet bore length & $L$ & $16 \mathrm{~mm}$ \\
Guide pipe diameter & $D_{p}$ & $44 \mathrm{~mm}$ \\
Guide pipe length & $L_{p}$ & $46 \mathrm{~mm}$ \\
\hline
\end{tabular}

previous study [16]. The nozzle was scanned across the specimen at a constant velocity for uniform treatment.

The processing time per unit length, $t_{p}$, is defined by the scanning speed, $v$, and the number of scans, $n$, as follows:

$$
t_{p}=\frac{n}{v}
$$

In the present experiment, $t_{p}$, was set to $10 \mathrm{~s} / \mathrm{mm}$ for cavitation peening.

The specimens were also treated by shot peening using recirculating shot accelerated by a water jet [18], as shown in Figure 3. The shot used in this study were JIS SUS440C metallic particles. The diameter and the number of shot were $3.2 \mathrm{~mm}$ and 500, respectively, and they were accelerated by a water jet with an injection pressure of $12 \mathrm{MPa}$ through three orifices of $0.58 \mathrm{~mm}$ in diameter. The standoff distance from the orifice plate to the specimen was $50 \mathrm{~mm}$. The head part shown in Figure 3(b) was scanned across the specimen along the guide by a motor. The processing time per unit length, $t_{p}$, was set to $0.2 \mathrm{~s} / \mathrm{mm}$. In order to treat the specimens with the same aggressive intensity as cavitation peening, the processing time for shot peening was chosen as $t_{p}=0.2$ $\mathrm{s} / \mathrm{mm}$ following evaluation of the arc height of an almen strip, which was $0.25 \mathrm{~mm}$ by cavitation peening with a 


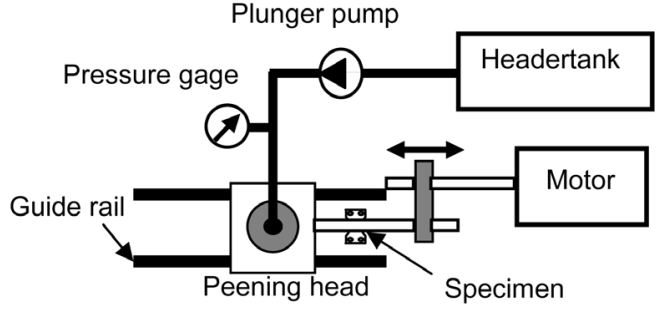

(a)Top view of shot peening system.

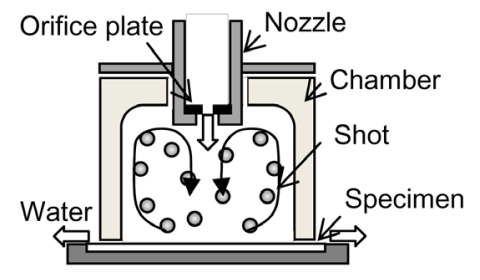

(b)Schematic diagram of peening head.

Figure 3. Schematic diagram of shot peening system using a water jet.

processing time of $t_{p}=10 \mathrm{~s} / \mathrm{mm}$.

All the specimens undergoing tests were manufactured by EBM. The powder for EBM was made of Ti-6Al$4 \mathrm{~V}$ alloy and the size of the powder was about $75 \mu \mathrm{m}$ in diameter. The spot size of the electron beam for selectively melting was $0.2 \mathrm{~mm}$ and the stacking pitch was $50 \mu \mathrm{m}$ in the direction of the thickness. The as-built specimens were $90 \mathrm{~mm}$ long, $30 \mathrm{~mm}$ wide and $4 \mathrm{~mm}$ thick as shown Figure 4. The width of center part was $20 \mathrm{~mm}$ with curvature radius of $45 \mathrm{~mm}$. The surfaces of the as-built specimens were extremely rough, which may lead to cracks under fatigue cycling. After manufacturing the specimens by EBM, the surfaces of some specimens were ground to remove the roughness so that their fatigue lives could be compared with the as-built specimens. The ground specimens were denoted as "as-machined". The thickness of the "as-machined" specimens were 2 $\mathrm{mm}$. Six types of specimen were prepared; As-built non-peened (NP), As-built cavitation peened (CP), As-built shot peened (SP), As-machined non-peened (NP), As-machined cavitation peened (CP), and As-machined shot peened (SP). In addition, the edges of all the specimens were polished by emery paper to prevent crack initiation from the edge.

A plate bending fatigue test is a suitable test for examining the effects of the surface mechanical properties on fatigue fracture. It has been demonstrated using plate bending tests that peening enhances the fatigue properties [19]. Therefore, a displacement controlled plate bending fatigue tester was used to evaluate the fatigue life of the specimens. All specimens were subject to bending stress with a stress ratio of $R=-1$. The frequency of the fatigue was set to $5 \mathrm{~Hz}$ for the first $10^{6}$ cycles and then changed to $10 \mathrm{~Hz}$ beyond that. The residual stress at the surface was evaluated by a two-dimensional XRD (2D-XRD) method. The measurements were carried out using $\mathrm{Cu} \mathrm{K} \alpha \mathrm{X}$-rays from a tube operated at $35 \mathrm{kV}$ and $40 \mathrm{~mA}$ through a $0.8 \mathrm{~mm}$ diameter collimator. Diffractive Xrays from the $\mathrm{Ti}\left(\begin{array}{lll}2 & 1 & 3\end{array}\right)$ lattice plane were detected using a two-dimensional position sensitive proportional counter with a diffractive angle of 140 degrees. Seventeen diffraction rings, i.e., Debye rings, were collected from several angles. The angle was chosen with reference to the previous study [20]. The exposure time was 120 s. Surface roughness measurements were conducted using a stylus with a tip diameter of $4 \mu \mathrm{m}$, a cutoff length of $0.8 \mathrm{~mm}$, and a sampling length of $4 \mathrm{~mm}$. The average surface roughness and maximum roughness were obtained from the average of five sets of experimental data.

\section{Results and Discussion}

Figure 5 shows the amplitude of the bending stress, $\sigma_{a}$, as a function of the number of cycles to failure, $N_{f}$, for specimens in all conditions, i.e., the $S-N$ curve. For the as-machined specimens, we focused on fatigue lives of less than $10^{6}$ cycles. As shown in Figure 5, the fatigue life of the as-built specimen is lowest and both cavitation peening and shot peening extend its life considerably. The fatigue strength can be defined as the stress at which the fatigue life becomes beyond $10^{7}$ cycles and it can be calculated by Little's method [21]. The fatigue strengths for the as-built NP, SP and CP specimens are 162.1, 195.8 and 197.0 MPa, respectively. The fatigue strength has increased by almost $21 \%$ by cavitation peening and shot peening. In the case of the as-machined specimens, the straight lines are given by the following equation with the assumption that the gradients of the SP and CP specimens are the same as that of the NP specimen:

$$
\sigma_{a}=-249 \log N_{f}+C
$$

The gradient is obtained from the dataset of the as-machined NP specimen. $C$ denotes the $y$-intercept, which is 1652 for NP, 1715 for SP and 1762 for CP. The fatigue life of the as-machined specimen has been extended by 


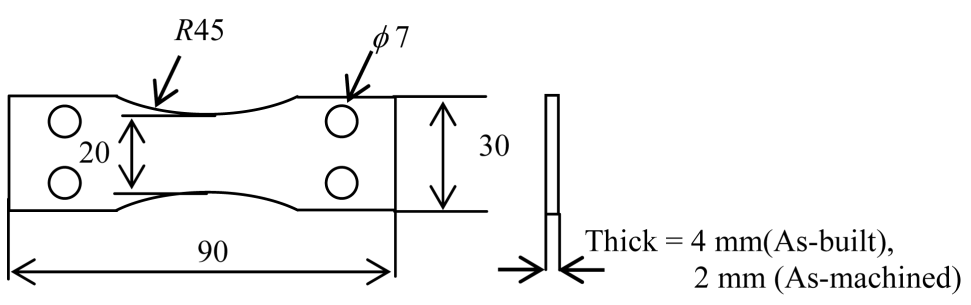

Figure 4. Geometry and dimensions of specimen for plate bending fatigue test.

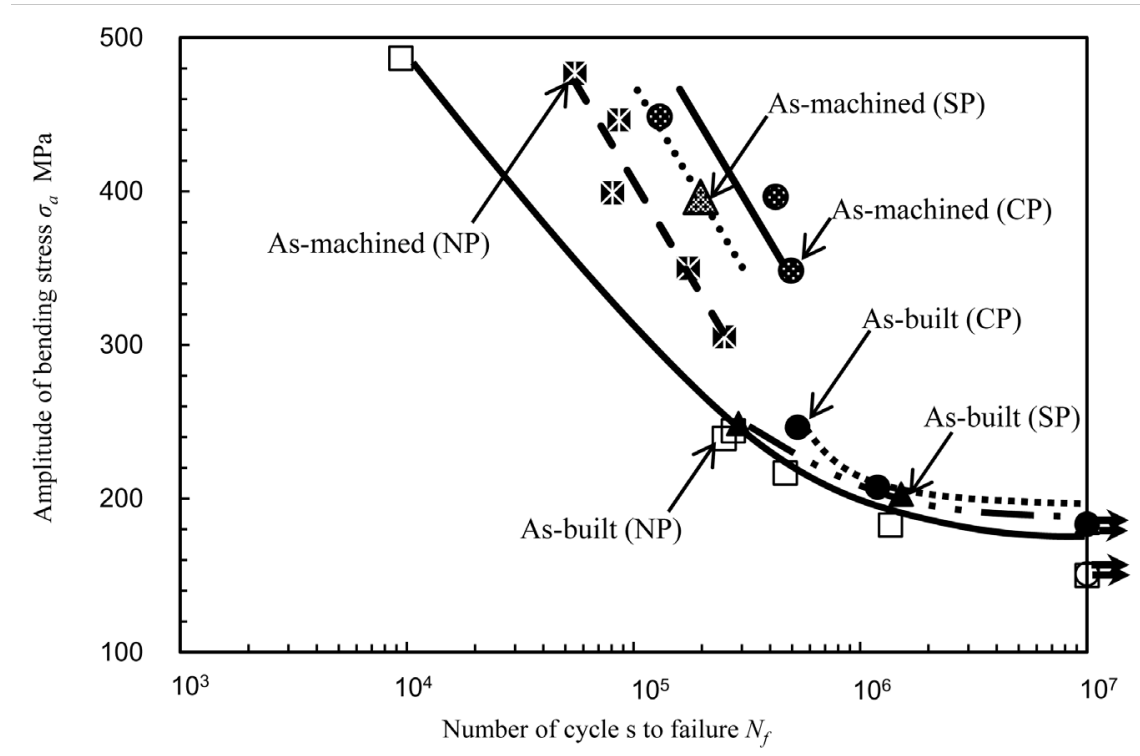

Figure 5. Enhancement of the fatigue strength of Ti-6Al-4V specimens manufactured by EBM by cavitation peening and shot peening.

both shot peening and cavitation peening. In order to compare the fatigue life at constant bending stress, the estimated number of cycles to failure, $N_{E}$, at a bending stress of $\sigma_{a}=400 \mathrm{MPa}$ was calculated by the following equation:

$$
N_{E}=10^{\frac{400-C}{24.9}}
$$

As shown in Figure 6, the estimated fatigue lives, $N_{E}$, at $\sigma_{a}=400 \mathrm{MPa}$ are 106,444, 191,179, and 295,423 for the NP, SP, for CP specimens, respectively. The fatigue life has been extended by $80 \%$ and $178 \%$ by shot peening and cavitation peening, respectively. This effect can probably be attributed to compressive residual stress at the surface introduced by peening. Figure 7 shows the residual stress, $\sigma_{R}$, in the bending direction at the surface of the as-built NP, SP, and CP and as-machined NP, SP, and CP specimens. The positive and negative values represent tension and compression, respectively. There is a tensile residual stress of $67 \pm 18 \mathrm{MPa}$ at the surface of the as-built NP specimen and this is mitigated and changed from tension to compression by peening. Compressive residual stresses of $127 \pm 30$ and $194 \pm 34 \mathrm{MPa}$ are introduced by shot peening and cavitation peening, respectively. There is a compressive residual stress of $220 \pm 27 \mathrm{MPa}$ in the as-machined NP specimen due to the machining. The value increases to $348 \pm 26 \mathrm{MPa}$ by shot peening and $648 \pm 20 \mathrm{MPa}$ by cavitation peening. Cavitation peening introduces high compressive residual stress since cavitation bubbles collapsing produce very high impact of the order of gigapascals and beyond, which are more severe than the impact produced by collisions between shot and the surface. Also, the strain velocity when the impact due to bubble collapsing deforms the surface is much higher than that produced by the impact of shot [22]. This difference gives rise to the differences in compressive residual stress and, as a result, the longer fatigue life. The diffractive $\mathrm{X}$-ray profiles made for the stress measurements include much information about the microstructure. This is true, in particular, of the full width at half maximum (FWHM) of the profile, from which information about the micro-strain in the grains 


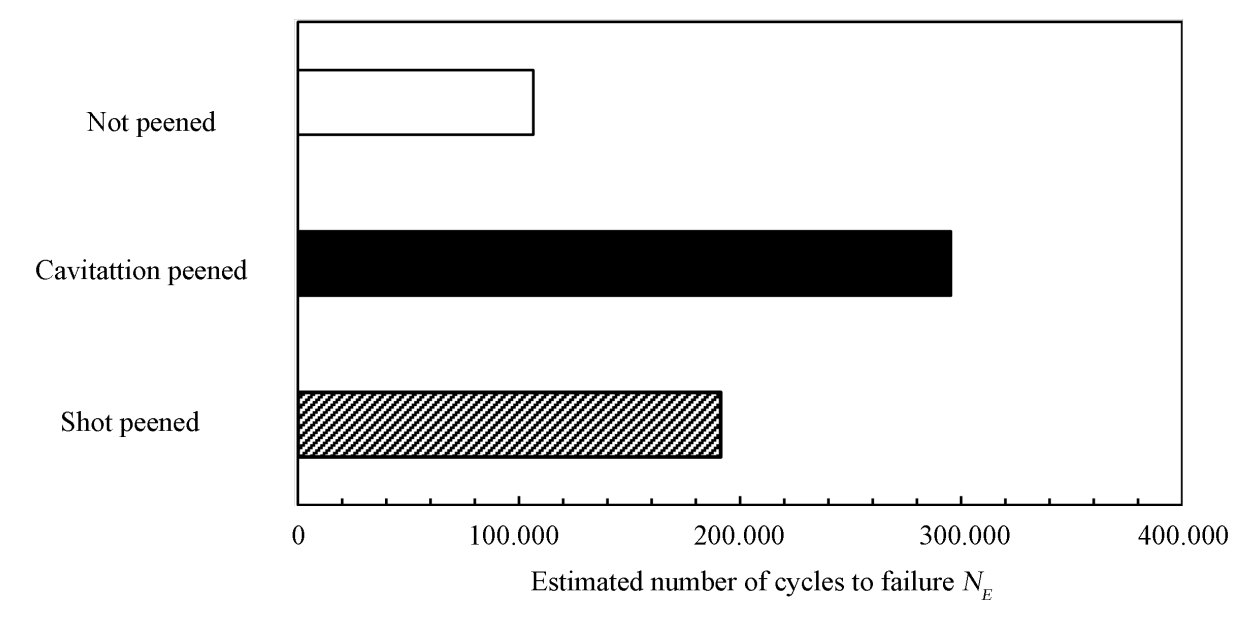

Figure 6. Extension of the fatigue life at $\sigma_{a}=400 \mathrm{MPa}$ for as-machined specimens.

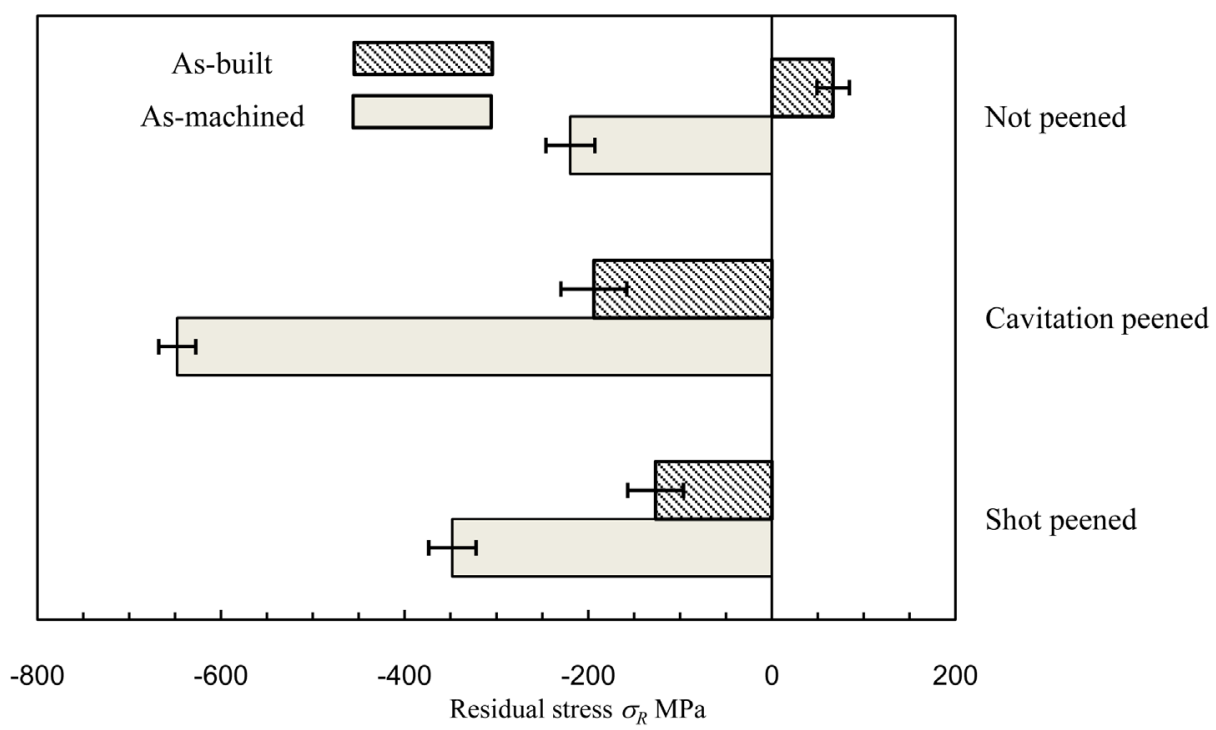

Figure 7. Introduction of compressive residual stress by cavitation peening and shot peening.

can be obtained. The micro-strain represents the strain caused by adjacent grains and random strain in the grains. The FWHM in the as-built specimens are 1.128 deg for the NP specimen, 2.307 deg for the SP specimen, and $1.960 \mathrm{deg}$ for the CP specimen. The value increases with peening since the melted surface is work hardened by the impact produced. That is, many dislocations are introduced by work hardening and these are refined as a result of the peening. However, the values in the as-machined specimens are 1.692 deg for the NP specimen, 1.861 deg for the SP specimen, and 1.662 deg for the CP specimen, which, in comparison with the as-built NP specimen have increased, which is a consequence of the work hardening induced by the machining. Interestingly, cavitation peening decreases the FWHM as opposed to shot peening even though a compressive residual stress is also introduced. In past literature, it has been shown that cavitation peening can decrease the FWHM while also introducing compressive residual stresses in titanium alloy rods made of Ti-6Al-4V [23]. It is likely that the ultrasound produced by cavitation bubbles collapsing moves dislocations, which may be the source of the microstrain [24]. Since it is possible that the micro-strain is the origin for crack initiation, the decrease in the FWHM can be seen as a beneficial effect for improving the fatigue life.

In general, one of the most important factors affecting the fatigue life in addition to the residual stress is surface roughness [25]. A roughened surface promotes crack initiation due to stress concentration. Figure 8 shows the surfaces of each of the specimens. Moreover, the arithmetic average roughness, $R a$, and maximum roughness, 


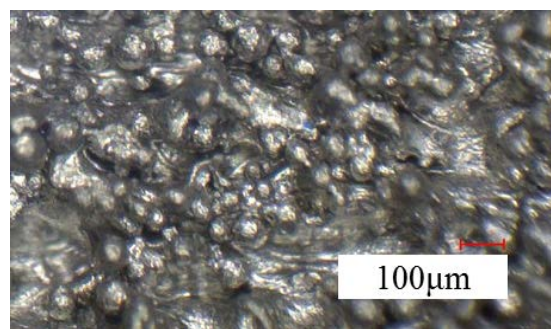

(a)

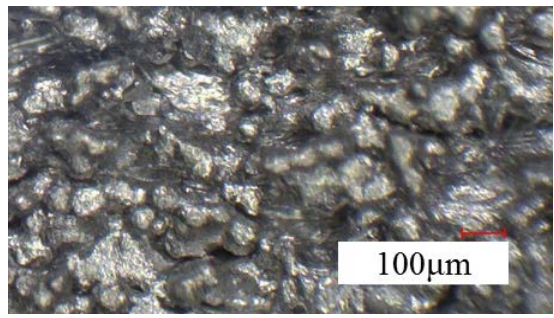

(b)

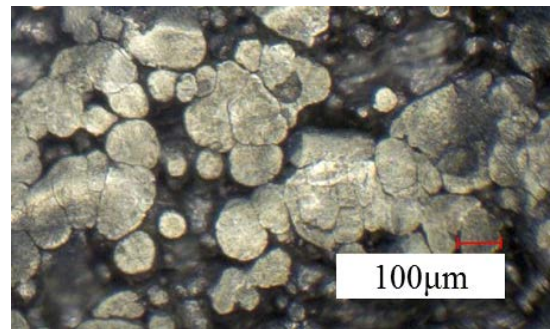

(c)

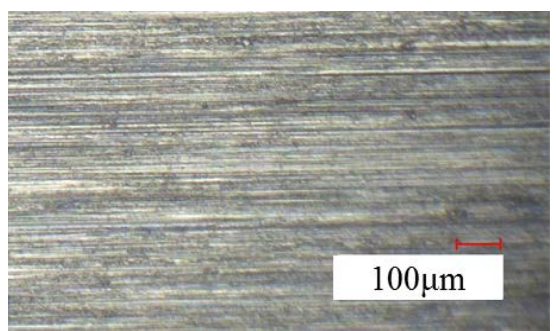

(d)

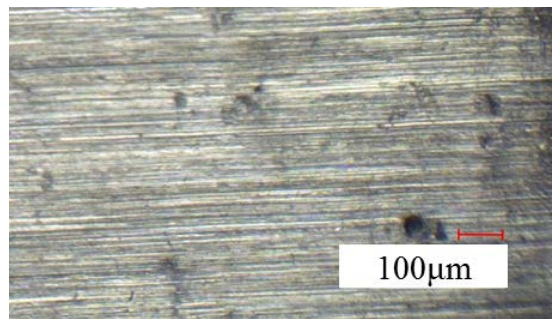

(e)

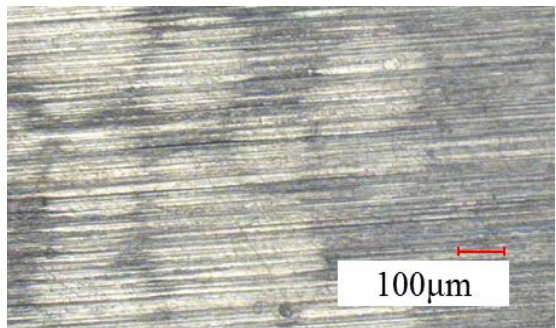

(f)

Figure 8. Surface of the specimens. (a) As-built (NP). (b) As-built (CP). (c) As-built (SP). (d) As-machined (NP). (e) As-machined (CP). (f) As-machined (SP).

$R z$, are shown in Figure 9. Particles stacked by EBM can be seen at the surface of the as-built NP specimen as shown in Figure 8(a). These particles make the surface extremely rough. $R a$ and $R z$ are $16.29 \pm 1.85$ and $83.53 \pm$ $5.23 \mu \mathrm{m}$, respectively, for the as-built NP specimen. Stacked particles can also be observed in the CP specimen whereasthe impact of the shot in shot peening makes the surface flatter. In cavitation peening, cavitation bubbles enter the gaps between the particles and introduce compressive residual stress at the bottoms of the gaps. This isshown by the results of the roughness measurements; $(R a, R z)=(7.15 \pm 0.89,41.19 \pm 6.51) \mu \mathrm{m}$ for the SP specimen and (16.13 $\pm 1.82,82.24 \pm 2.83) \mu \mathrm{m}$ for the CP specimen. Since, unlike cavitation bubbles, shot cannot reach the bottoms of the gaps between the particles where the fatigue cracks initiate, the difference in roughness between the SP and CP specimens does not correlate with the increase in fatigue life. This supports the fact that the introduction of compressive residual stress into the as-built specimen by shot peening is less than that by cavitation peening. In the as-machined specimens, the surface roughness is dramatically improved by the machining; $(R a, R z)=(0.22 \pm 0.03,1.51 \pm 0.40) \mu \mathrm{m}$ for the NP specimen. The surface roughness of the CP specimen is higher than that of the SP specimen; $(R a, R z)=(0.32 \pm 0.02,2.23 \pm 0.461) \mu \mathrm{m}$ for the SP specimen and $(0.53 \pm 0.08,3.14 \pm 0.38) \mu \mathrm{m}$ for the CP specimen. This is because the impact due to cavitation bubbles collapsing forms local, deep plastic deformation pits at the surface even though the surface has a high yield stress. In contrast, wide and shallow deformation marks can be observed in the SP specimen. That is, the impact of shot in this experiment was unable to induce large plastic deformation in the sub-surface of the Ti-6Al-4V specimens. It is quite likely that the difference in the compressive residual stress can be attributed to the differences between the plastic deformation pits. In order to examine the combined effect of the compressive residual stress and surface roughness on fatigue failure, we introduce a parameter, $R_{\sigma}^{*}$, given by Equation (4) [26], in which the compressive residual stress has a positive effect and the surface roughness has a negative effect on the fatigue life: 


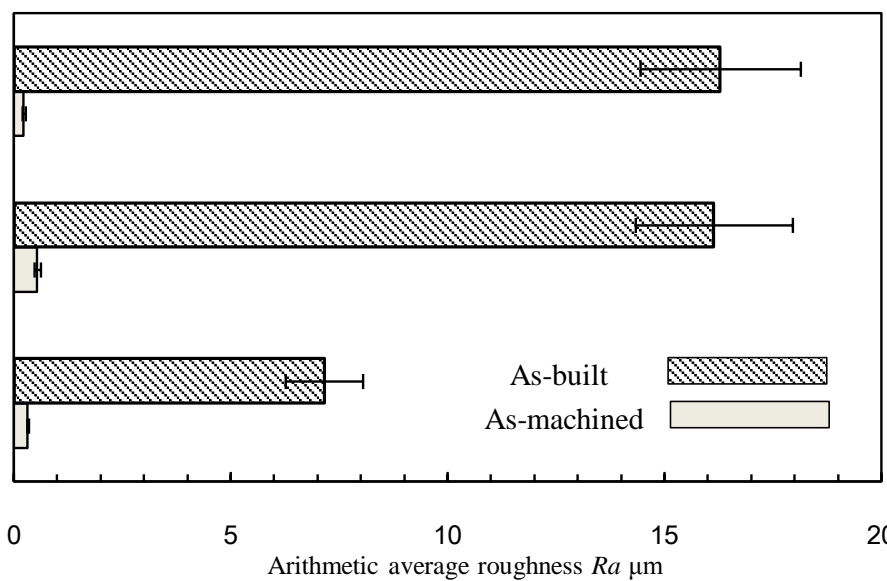

Not peened

Cavitation peened

Shot peened

(a)

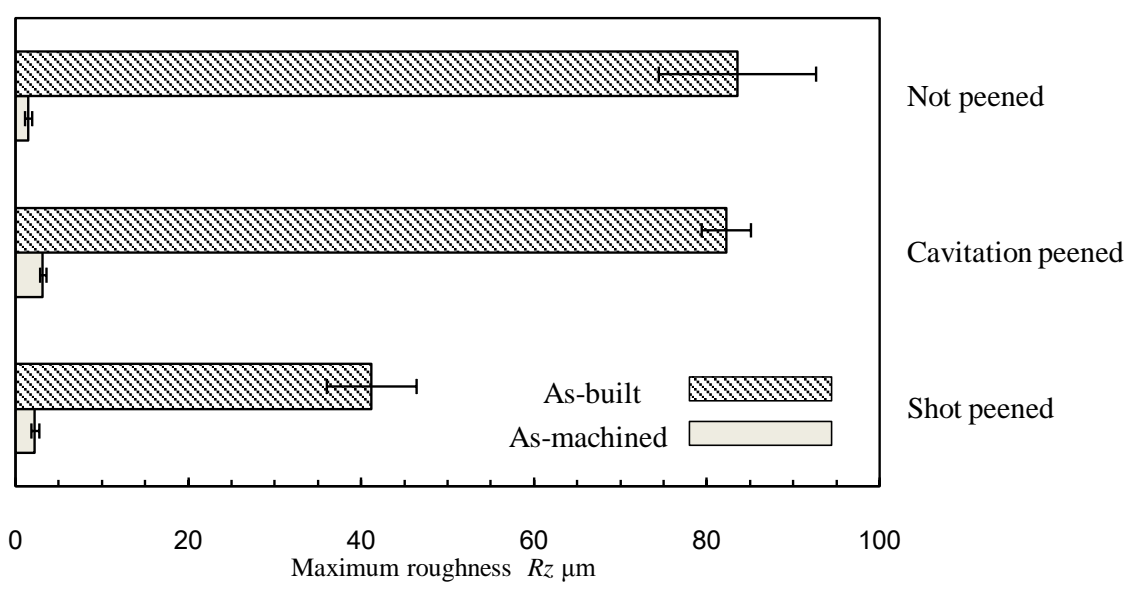

(b)

Figure 9. Variation of the surface roughness by cavitation peening and shot peening. (a) Arithmetic average roughness $R a$. (b) Maximum roughness $R z$.

$$
R_{\sigma}^{*}=\frac{\sigma_{C R}^{2}}{R a}
$$

where $\sigma_{C R}$ denotes the compressive residual stress at the surface. Other than the value of the compressive residual stress, another factor that has a positive effecton fatigue life is the depth of the compressive residual stress. Thus, the square of the compressive residual stress is included in $R_{\sigma}^{*}$. Figure10 plots the estimated fatigue life at $\sigma_{a}=400 \mathrm{MPa}, N_{E}$, versus the parameter $R_{\sigma}^{*}$ for as-machined specimens. As shown in Figure 10, the fatigue life increases linearly with $R_{\sigma}^{*}$. Thus, this parameter is a good indicator for the fatigue life. That is, the beneficial effects of peening on the fatigue life can be indicated by considering the surface roughness and compressive residual stress.

Finally, Figure 11 shows cross sections of the fractured surfaces of the specimens. It seems that small cracks initiate at various points near the surface, propagate along the surface and into the depth, e.g., semi-elliptical in shape, and coalesce with each other. After they coalescence, a high stress intensity factor, which represents the magnitude of the stress field, around a large crack leads to unstable and rapid fatigue crack propagation. The compressive residual stress mitigates the actual applied stress and also causes a crack closure effect [27] [28] when cracks occur at the surface, since the residual stress affects the stress field around the crack tip, i.e., the stress intensity factor [29]. Therefore the stress field near the surface and around the crack tip after crack initiation can be greatly reduced by compressive residual stress. Although components and structures manufactured by EBM have low resistance to fatigue failure, peening, especially cavitation peening, can greatly increase it and 


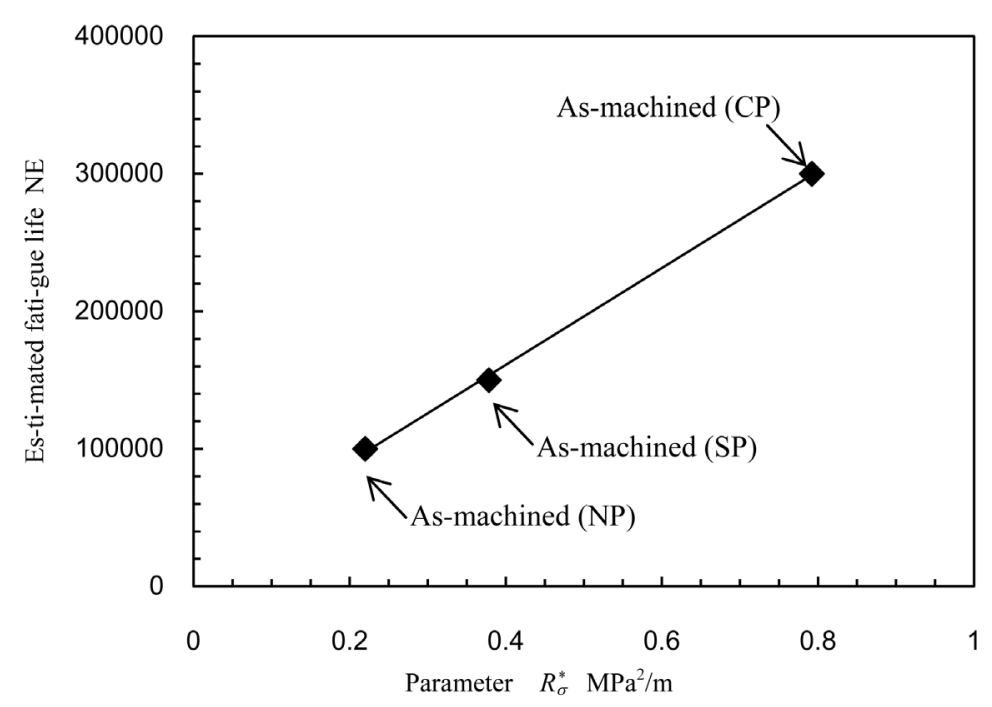

Figure 10. Linear relationship between the estimated fatigue life at $\sigma_{a}=400 \mathrm{MPa}$ for as-machined specimens and the indicative parameter which is a function of the compressive residual stress and the surface roughness.

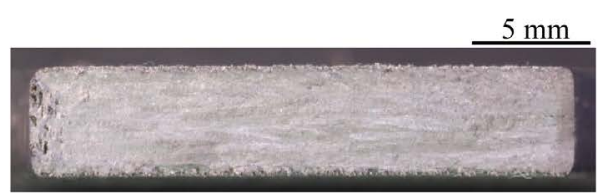

(a)

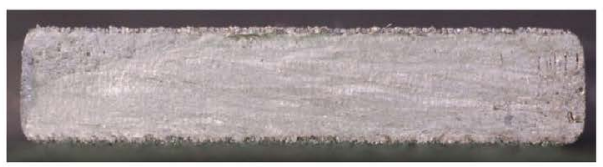

(b)

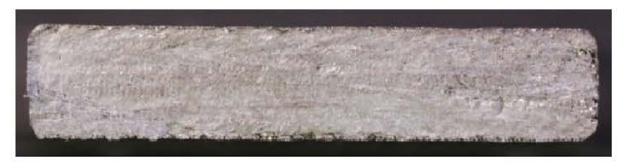

(c)

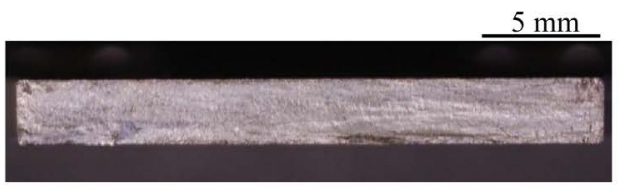

(d)

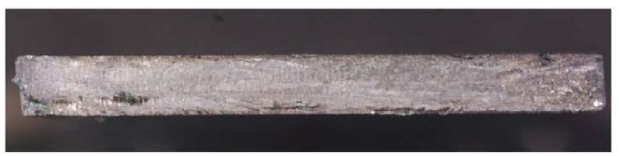

(e)

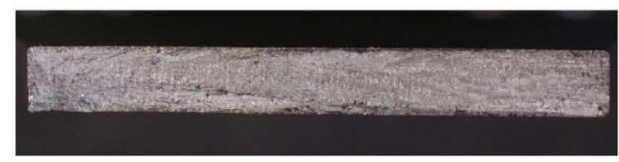

(f)

Figure 11. Cross sectional view of the fractured surfaces. (a) As-built (NP). (b) As-built (CP). (c) As-built (SP). (d) As-machined (NP). (e) As-machined (CP). (f) As-machined (SP).

extend the fatigue life by introducing compressive residual stress at the surface.

\section{Conclusions}

In order to demonstrate that the fatigue life of metallic material manufactured by Electron beam melting (EBM) can be improved by cavitation peening, specimens manufactured by EBM using Ti-6Al-4V powder were treated by cavitation peening. For comparison, specimens were also treated with shot peening. Two types of specimens, as-built specimens and as-machined specimens, were prepared. The as-machined specimens were prepared by removing the surface roughness, which was due to stacked particles, from the as-built specimens by machining. The fatigue life, i.e., the $S-N$ curve, was evaluated using a displacement controlled plate bending fatigue tester, and the residual stress at the surface was measured by an X-ray diffraction method. Moreover, the surface roughness, i.e., the average roughness, $R a$, and the maximum roughness, $R z$, was measured by a scanning stylus method. The results obtained are summarized as follows: 
1) Specimens manufactured by EBM have low fatigue resistance and their fatigue lives can be improved by cavitation peening more effectively than by shot peening. In the present experiments, the fatigue strength, which is the applied stress at which the fatigue life goes beyond $10^{7}$ cycles for the as-built specimens, is increased from $162 \mathrm{MPa}$ to $195 \mathrm{MPa}$ by shot peening and to $197 \mathrm{MPa}$ by cavitation peening. For the as-machined specimens, the fatigue life at an applied stress of $400 \mathrm{MPa}$ was increased by $80 \%$ by shot peening and $178 \%$ by cavitation peening.

2) Cavitation peening introduced a compressive residual stress of $194 \pm 34 \mathrm{MPa}$ even though the surface of the as-built specimen was extremely rough $(R a=16.29 \pm 1.85 \mu \mathrm{m}, R z=83.53 \pm 5.23 \mu \mathrm{m})$. Shot peening introduced a compressive residual stress of $127 \pm 30 \mathrm{MPa}$ in the as-built specimen. Regarding the as-machined specimens $(R a=0.22 \pm 0.03 \mu \mathrm{m}, R z=1.51 \pm 0.40 \mu \mathrm{m})$, shot peening and cavitation peening introduced compressive residual stresses of $348 \pm 26$ and $648 \pm 20 \mathrm{MPa}$, respectively. With regard to cavitation peening the full width at half maximum (FWHM) in the X-ray diffraction profile, which was related to the microstrain, decreased from 1.692 deg to 1.662 deg, while further work hardening was introduced. In contrast shot peening increased the FWHM to $1.861 \mathrm{deg}$. It is possible that the increase in micro-strain is the origin of the crack initiation.

3) The effect of peening on fatigue can be represented by a parameter that depends on a combination of the compressive residual stress, which has a positive effect, and the surface roughness, which has a negative effect. In the present study, the increase in fatigue life was found to have a linear relationship with the parameter.

\section{Acknowledgements}

This work was partly supported by Next Generation Automobiles in Miyagi. The authors thank Mr. M. Mikami, technician, Tohoku University for his help with the experiments.

\section{References}

[1] Edwards, P., O’Conner, A. and Ramulu, M. (2013) Electron Beam Additive Manufacturing of Titanium Components: Properties and Performance. Journal of Manufacturing Science and Engineering, 135, 061016. http://dx.doi.org/10.1115/1.4025773

[2] Brandl, E., Baufeld, B., Leyens, C. and Gault, R. (2010) Additive Manufactured Ti-6Al-4V Using Welding Wire: Comparison of Laser and Arc Beam Deposition and Evaluation with Respect to Aerospace Material Specifications. Physics Procedia, 5, 595-606. http://dx.doi.org/10.1016/j.phpro.2010.08.087

[3] Baufeld, B., Van der Biest, O. and Gault, R. (2010) Additive Manufacturing of Ti-6Al-4V Components by Shaped Metal Deposition: Microstructure and Mechanical Properties. Material and Design, 31, S106-S111. http://dx.doi.org/10.1016/j.matdes.2009.11.032

[4] Wycisk, E., Solbanch, A., Siddique, S., Herzog, D., Walther, F. and Emmelmann, C. (2014) Effects of Defects in Laser Additive Manufactured Ti-6Al-4V on Fatigue Properties. Physics Procedia, 56, 371-378. http://dx.doi.org/10.1016/j.phpro.2014.08.120

[5] Baufeld, B. and Van der Biest, O. (2009) Mechanical Properties of Ti-6Al-4V Specimens Produced by Shaped Metal Deposition. Science and Technology of Advanced Materials, 10, 015008. http://dx.doi.org/10.1088/1468-6996/10/1/015008

[6] Champoux, R.L., Underwood, J.H. and Kapp, J.A. (1988) Analytical and Experimental Methods for Residual Stress Effects in Fatigue. American Society for Testing and Materials Special Technical Publication STP 1004. http://dx.doi.org/10.1520/stp1004-eb

[7] Takakuwa, O., Yamamiya, K. and Soyama, H. (2012) An Indicator for the Suppression of Fatigue Crack Growth by Hybrid Peening. Journal of Solid Mechanics and Materials Engineering, 3, 357-371.

[8] Takakuwa, O. and Soyama, H. (2015) Effect of Residual Stress on the Corrosion Behavior of Austenitic Stainless Steel. Advances in Chemical Engineering and Science, 5, 62-71. http://dx.doi.org/10.4236/aces.2015.51007

[9] Wang, S.P., Li, Y.J., Yao, M. and Wang, R.Z. (1998) Compressive Residual Stress Introduced by Shot Peening. Journal of Materials Processing Technology, 73, 64-73. http://dx.doi.org/10.1016/S0924-0136(97)00213-6

[10] Soyama, H., Saito, K. and Saka, M. (2002) Improvement of Fatigue Strength of Aluminum Alloy by Cavitation Shotless Peening. Journal of Engineering Materials and Technology, 124, 135-139. http://dx.doi.org/10.1115/1.1447926

[11] Soyama, H. (2011) Enhancing the Aggressive Intensity of a Cavitating Jet by Means of the Nozzle Outlet Geometry. Journal of Fluids Engineering, 133, 101301. 
[12] Soyama, H., Macodiyo, D.O. and Mall, S. (2004) Compressive Residual Stress into Titanium Alloy Using Cavitation Shotless Peening Method. Tribology Letters, 17, 501-504. http://dx.doi.org/10.1023/B:TRIL.0000044497.45014.f2

[13] Soyama, H. (2014) The Use of Cavitation Peening to Increase the Fatigue Strength of Duralumin Plates Containing Fastener Holes. Materials Sciences and Applications, 5, 430-440. http://dx.doi.org/10.4236/msa.2014.56047

[14] Soyama, H. and Sekine, Y. (2010) Sustainable Surface Modification Using Cavitation Impact for Enhancing Fatigue Strength Demonstrated by a Power Circulating-Type Gear Tester. International Journal of Sustainable Engineering, 3, 25-32. http://dx.doi.org/10.1080/19397030903395174

[15] Soyama, H., Shimizu, M., Hattori, Y. and Nagasawa, Y. (2008) Improving the Fatigue Strength of the Elements of a Steel Belt for CVT by Cavitation Peening. Journal of Materials Science, 43, 5028-5030. http://dx.doi.org/10.1007/s10853-008-2743-6

[16] Soyama, H. (2014) Enhancing the Aggressive Intensity of a Cavitating Jet by Introducing a Cavitator and a Guide Pipe. Journal of Fluid Science and Technology, 9, JFST0001-1-12. http://dx.doi.org/10.1007/s10853-008-2743-6

[17] Soyama, H. (2011) Corrosion Behavior of Pressure Vessel Steel Exposed to Residual Bubbles after Cavitation Bubble Collapse. Corrosion, 67, 025001-1-025001-8. http://dx.doi.org/10.5006/1.3548733

[18] Naito, A., Takakuwa, O. and Soyama, H. (2012) Development of Peening Technique Using Recirculating Shot Accelerated by Water Jet. Material Science and Technology, 28, 234-239. http://dx.doi.org/10.1179/1743284711Y.0000000027

[19] Soyama, H. (2007) Improvement of Fatigue Strength by Using Cavitating Jets in Air and Water. Journal of Materials Science, 42, 6638-6641. http://dx.doi.org/10.1007/s10853-007-1535-8

[20] Takakuwa, O. and Soyama, H. (2013) Optimizing the Conditions for Residual Stress Measurement Using a Two-Dimensional XRD Method with Specimen Oscillation. Advances in Materials Physics and Chemistry, 3, 8-18. http://dx.doi.org/10.4236/ampc.2013.31A002

[21] Little, R.E. (1972) Estimating the Median Fatigue Limit for Very Small Up-and-Down Quantal Response Tests and for S-N Data with Runouts. American Society for Testing and Materials Special Technical Publication STP511, 29-42.

[22] Kanou, S., Takakuwa, O., Mannava, S.R., Qian, D., Vasudevan, V.K. and Soyama, H. (2012) Effect of the Impact Energy of Various Peening Techniques on the Induced Plastic Deformation Region. Journal of Materials Processing Technology, 212, 1998-2006. http://dx.doi.org/10.1016/j.jmatprotec.2012.05.003

[23] Takakuwa, O., Gill, A.S., Ramakrishnan, G., Mannava, S.R., Vasudevan, V.K. and Soyama, H. (2013) Introduction of Compressive Residual Stress by Means of Cavitation Peening into a Titanium Alloy Rod Used for Spinal Implants. Materials Sciences and Applications, 4, 23-28. http://dx.doi.org/10.4236/msa.2013.47A2004

[24] Soyama, H. and Yamada, N. (2008) Relieving Micro-Strain by Introducing Macro-Strain in a Polycrystalline Metal Surface by Cavitation Shotless Peening. Materials Letters, 62, 3564-3566. http://dx.doi.org/10.1016/j.matlet.2008.03.055

[25] Maiya, P.S. and Busch, D.E. (1975) Effect of Surface Roughness on Low-Cycle Fatigue Behavior of Type 304 Stainless Steel. Metallurgical Transactions A, 6, 1761-1766. http://dx.doi.org/10.1007/BF02642305

[26] Takakuwa, O. and Soyama. (2014) Application of Re-circulating Shot Peening Method Using a Water Jet to Spinal Implant Rod. Journal of Jet Flow Engineering, 31, 20-27 (in Japanese).

[27] Beghini, M. and Bertini, L. (1990) Fatigue Crack Propagation through Residual Stress Field with Closure Phenomena. Engineering Fracture Mechanics, 36, 379-387. http://dx.doi.org/10.1016/0013-7944(90)90285-O

[28] Knowles, D.M., Downes, T.J. and King, J.E. (1993) Crack Closure and Residual Stress Effects in Fatigue of a ParticleReinforced Metal Matrix Composite. Acta Metallurgica et Materialia, 41, 1189-1196. http://dx.doi.org/10.1016/0956-7151(93)90167-Q

[29] Lads, D.A., Apelian, D. and Donald, J.K. (2007) Fracture Mechanics Analysis for Residual Stress and Crack Closure Corrections. International Journal of Fatigue, 29, 687-694. http://dx.doi.org/10.1016/j.ijfatigue.2006.07.002 